\title{
Determinação das histórias de amor mais adequadas para descrever relacionamentos amorosos e identificação das histórias de amor que produzem mais identificação, menos identificação e que as pessoas mais gostariam de viver
}

\author{
Ailton Amélio da Silva \\ Andréa Soutto Mayor \\ Thiago de Almeida \\ Adriana Guimarães Rodrigues \\ Luiz Maurício de Oliveira \\ Mônica Martinez. \\ Universidade de São Paulo (USP)
}

\begin{abstract}
RESUMO
Esta pesquisa teve dois objetivos: 1) verificar se as histórias de amor descritas por Sternberg (1996) são úteis para a realização de quatro tarefas: (a) descrever os relacionamentos amorosos atuais/últimos dos participantes da pesquisa (b) identificar as histórias de amor que estes mais se identificavam, (c) identificar as histórias de amor que estes menos se identificam e (d) identificar as histórias que estes mais desejariam viver e (2) verificar se há relação entre as respostas apresentadas nestas quatro tarefas. Trinta e oito homens e trinta e oito mulheres, estudantes universitários, responderam a quatro questões, uma para cada das quatro tarefas acima. Todas as 24 histórias foram utilizadas para responder a pelo menos uma destas quatro tarefas, por pelo menos um dos participantes. Onze das 24 histórias foram mais utilizadas nas tarefas (a), (b) e (d), acima. Dezessete histórias de amor foram utilizadas na tarefa (c) acima. As quantidades de usos das histórias nestas quatro tarefas apresentaram correlações estatisticamente significantes. As respostas de homens e mulheres a estas quatro tarefas foram semelhantes (as correlações de Pearson variaram entre -0,43 e 0,92). Estes resultados confirmam a utilidade das histórias para descrever e avaliar estes diferentes aspectos de um relacionamento amoroso.
\end{abstract}

Palavras-chave: amor; histórias de amor; relacionamentos; escolha de parceiros.

\begin{abstract}
Determination love stories more adjusted to describe loving relationships and identification of love stories that produce more identification, little identification and that the people more would like to live

This research had two objectives: 1) to verify if the love stories described by Sternberg (1996) are useful for the accomplishment of four tasks: (a) to describe the current/last loving relationships of the participants of the research (b) to identify love stories they were more identified, (c) t to identify love stories that they were less identified and (d) identify the love stories that they would like to live and (2) to verify if there is any relation between the answers presented on these four tasks. Thirty-eight men and thirty-eight women, university students, answered four questions, one for each of the four tasks above. All 24 histories were used to answer at least one of these four tasks, for at least one of the participants. Eleven of 24 stories were used in the tasks (a), (b) and (d). Seventeen love stories were used in the task (c). The amounts of uses of stories in these four tasks presented correlations statistically significant. The answers of men and women to these four tasks were similar (the correlations of Pearson varied between $-0,43$ and 0,92). These results confirm the utility of these stories to describe and to evaluate different aspects of a loving relationship.
\end{abstract}

Keywords: love; love stories; relationships; choice of partners. 


\section{INTRODUÇÃO}

O amor é um sistema complexo e dinâmico que envolve cognições, emoções e comportamentos (Shaver; Hazan \& Bradshaw, 1988).

O amor é um dos principais requisitos para o casamento nos países ocidentais. Uma pesquisa realizada por Levine e colaboradores (1988) em onze países (inclusive no Brasil) apresentou evidências sobre a importância do amor como requisito para a escolha de um cônjuge. Estes autores pediram para pessoas destes países que respondessem à seguinte questão: "Se um homem/mulher tivesse todas as qualidades que você deseja, você se casaria com ele(a) mesmo se não o(a) amasse?" Haviam três opções de resposta: sim, não e indeciso. Homens e mulheres responderam a esta questão de uma forma semelhante. De acordo com os resultados desta pesquisa, os países participantes podiam ser classificados em dois grupos: aqueles onde o sim foi a resposta mais freqüente (Índia e Paquistão), e aqueles onde o não foi a resposta mais frequiente (todos os outros países pesquisados). Em nenhum dos países a resposta "indeciso" foi a mais frequiente. Os EUA e o Brasil foram os países que mais rejeitaram o casamento sem amor. No Brasil apenas $4,3 \%$ das pessoas disseram que se casariam sem amor, $10 \%$ ficaram indecisas e 85,7\% disseram que não se casariam sem amor. Os países coletivistas e/ou mais atrasados economicamente são aqueles onde as percentagens de indecisos foram muito grandes. Uma grande percentagem de indecisão parece indicar que estes países estão em uma fase de transição quanto ao papel que este sentimento deve desempenhar na escolha do cônjuge: o casamento arranjado está sendo substituído pelo casamento onde os parceiros é que se escolhem e, neste caso, o amor é um dos principais critérios de escolha.

Outras evidências atestam a importância deste sentimento na escolha do cônjuge. Todas estas evidências indicam que a escolha de parceiros amorosos não é aleatória (Buss, 1994). Esta seleção é guiada por princípios que ajudam a decidir quais são as prioridades e os atributos desejados num parceiro amoroso (Amélio, 2001). David Buss e colaboradores (1990) realizaram uma pesquisa em 37 culturas, espalhadas por todos os continentes do nosso planeta (uma amostra brasileira foi incluída nesta pesquisa), com o intuito de verificar qual a importância que cada uma delas atribuía a 18 atributos para a escolha de um cônjuge. Nesta pesquisa, o requisito sentir atração mútua ou amor pelo parceiro foi aquele que obteve a maior média de importância. Este requisito foi considerado muito importante por praticamente todos os países ocidentais, como Brasil,
França, Estados Unidos e Inglaterra. Só em culturas não ocidentais é que foram constadas algumas exceções sobre a importância deste sentimento para esta finalidade, como por exemplo, entre os nigerianos.

Muita coisa tem sido dita sobre o amor. Este tema está presente na literatura, nos filmes, nas novelas, nas músicas e em grande parte das conversas que acontecessem no dia a dia. Longe de ser apenas conteúdo de filmes e livros, a procura pelos príncipes e pelas princesas encantadas continua a ser uma realidade vivenciada por muitas pessoas (Lemos, 1994). O modelo atual de casamento enfrenta muitos problemas (Gottman, \& Notarius, 2002; Pinzof, 2002) e o amor é um dos seus principais ingredientes, como vêm mostrando vários estudos nesta área. Mas, afinal quais são os fatores que produzem o surgimento e a duração do amor? Muitas são as abordagens e modelos teóricos que tentam responder a esta pergunta. Além de tudo que os leigos afirmam sobre este fenômeno existem muitas teorias científicas tentando explicá-lo.

Muitas destas teorias sobre o amor não são incompatíveis ente si, mas sim complementares, pois tratam de diferentes aspectos deste fenômeno. Por exemplo, a teoria Estilos de Amor (Lee, 1986) é apelativa, convincente, preditiva de outros fenômenos (caminhos para o apaixonamento, satisfação conjugal, ajuda a entender as prioridades na escolha de parceiros) e muito útil para classificar os tipos de amor. A Teoria Triangular (Sternberg, 1986), contribui para a compreensão dos ingredientes do amor (intimidade, paixão e compromisso) e como estes se combinam para gerar diferentes tipos deste sentimento. A teoria sociobiológica (Buss, 1986) ajuda a entender as funções para a espécie humana do amor e quais são os fatores que influenciam a escolha de parceiros e a traição. A Teoria do Apego Bowlby (1989) é muito elucidativa sobre as origens dos estilos de amor e a persistência destes estilos durante a vida. Esta teoria também explica as origens das diferenças individuais nas formas de amar. Segundo esta teoria, os diferentes tipos de amor romântico têm origem nos estilos de apego que são formados através das interações entre a criança e quem toma conta dela (Shaver, Hazan \& Bradshaw, 1986).

Estas teorias sobre o amor têm gerado muitas pesquisas e vêm mostrando que os diferentes estilos de amor estão associados com uma grande quantidade de fenômenos na área afetiva como, por exemplo, o número de parceiros sexuais que as pessoas têm durante a vida, a duração do casamento e a satisfação com o relacionamento (Hendrick \& Hendrick, 1992). 
Uma das mais interessantes teorias é a de Money (1986). Esta teoria propõe que aquilo que desperta a sexualidade e o que leva o ser humano a escolher um(a) parceiro(a) em detrimento de outro(a) é uma espécie de mapa amoroso inconsciente. Tais mapas, desenvolvidos por todas as pessoas entre os cinco e os oito anos de idade, configuram a proto-imagem do parceiro ideal. Segundo esta teoria, a relação afetiva seria iniciada quando uma pessoa encontra alguém que se encaixe nos parâmetros pré-definidos pelo seu mapa amoroso.

Outra teoria que também propõe a existência de "mapas amorosos" é a "histórias de amor", de Robert J. Sternberg (1996 e 1998) - professor de Psicologia da Universidade de Yale. Esta teoria interpreta o amor como uma história. Resumidamente, ela propõe que as experiências afetivas, que ocorrem desde o nascimento, fazem com que as pessoas desenvolvam histórias que as ajudam a identificar a quando o amor está ocorrendo, o modo como ele nasce e como ele se desenvolve. Nestas histórias os amantes têm características específicas e desempenham papéis bem definidos e complementares, tal como acontece em uma peça de teatro. $\mathrm{O}$ grau de complementaridade destes papéis é um dos principais determinantes do sucesso da relação. Este conjunto de características constitui uma espécie de script amoroso. Esta teoria é muito útil para entender a grande diversidade de fatores que são responsáveis pelo nascimento do amor e como diferentes tipos de relacionamentos amorosos podem produzir uniões que dão certo ou fracassam.

Sternberg (1996) realizou um estudo para identificar quais seriam estas histórias de amor. Neste estudo, em primeiro lugar, foram identificadas várias possíveis descrições de histórias de amor. Em seguida, este autor solicitou a diversas pessoas que usassem uma escala unipolar do tipo Likert para avaliar quanto elas se identificavam com cada uma destas histórias. Os resultados deste estudo indicaram que cada pessoa possui uma história individual sobre como deve ser uma ligação amorosa. Tais histórias, muitas vezes, são parcial ou totalmente inconscientes para quem a possui.

Esta é uma teoria muito promissora porque ajuda a entender a diversidade das formas de amar, o apaixonamento e as chances de um relacionamento amoroso entre duas pessoas ser bem sucedido. Esta teoria, no entanto, precisa ser mais bem fundamentada através de pesquisas. Por exemplo, as descrições das histórias de amor devem ser mais bem elaboradas e as suas incidências na população devem ser estimadas.

Não basta identificar qual a história de amor que melhor descreve um relacionamento entre duas pessoas.
Muitas vezes as histórias de amor que elas estão vivendo não corresponde à história de amor que cada uma delas mais se identifica (aquela que retrata melhor como cada uma é) e, também, estes dois tipos de história podem não coincidir com aquelas histórias que elas mais gostariam de viver. Fazendo uma analogia, uma pessoa pode não estar profissionalmente realizada se está trabalhando como empacotador (história que está vivendo), mas acha que tem vocação para a pintura (história que melhor se identifica), mas gostaria de ser uma escritora (história que mais gostaria de viver). Da mesma forma, as coincidências ou discrepâncias entre estes três tipos de histórias podem ter sérias implicações para suas satisfações e duração do relacionamento amoroso entre elas. Estes tipos de história constituem uma espécie de gabarito para avaliar os méritos e deméritos de um relacionamento amoroso que está ocorrendo (Buunk e Rusbult, 1993).

As histórias de amor que melhor descrevem seus relacionamentos atuais/últimos são úteis para descrever o que está ocorrendo em um dado relacionamento. As outras histórias são úteis para identificar os parâmetros que podem ser utilizados para diagnosticar e prognosticar possíveis motivos intrapsíquicos (por exemplo, discrepâncias entre histórias que mais se identifica e história que mais gostaria de viver) e interpsíquicos (por exemplo, discrepâncias entre a história que está vivendo e aquela que se identifica ou que mais gostaria de viver) para a insatisfação e fracasso destes relacionamentos (Levine, 1988). Estas histórias também podem ser utilizadas como guia para ajudar as pessoas a se conhecerem melhor (histórias que mais se identificam, histórias que menos se identificam e histórias que mais gostariam de viver), para se tratarem para escolher parceiros amorosos que tenham histórias compatíveis para aumentar as chances de que o relacionamento seja satisfatório e duradouro (Sternberg, 1996; Sternberg, 1998).

A presente pesquisa tem como objetivo verificar se as histórias de amor identificadas por Sternberg (1996) podem ser utilizadas para estudar diferentes aspectos de um relacionamento amoroso. Mais especificamente, esta pesquisa tem três objetivos:

(1) Verificar se as histórias de amor descritas por Sternberg (1996) são relevantes para descrever os seguintes quatro aspectos dos relacionamentos amorosos:

- Histórias de amor que melhor descrevem o que está acontecendo nos relacionamentos atuais/últimos dos participantes.

- Histórias de amor que os participantes da pesquisa mais se identificam. 
- Histórias de amor que os participantes menos se identificam.

- Histórias de amor que os participantes mais gostariam de viver.

(2) Verificar se homens e mulheres são similares ou diferentes quando utilizam as histórias de amor para executar as tarefas propostas no item anterior.

(3) Verificar se há relação entre aquelas histórias que os participantes da pesquisa estão vivenciando em seus relacionamentos amorosos atuais/últimos, aquelas histórias que mais se identificam, aquelas histórias de amor que menos se identificam e aquelas histórias de amor que mais gostariam de viver.

\section{MÉTODO}

\section{Participantes}

Fizeram parte deste estudo 76 estudantes universitários, cuja média de idade era de 28,4 anos. Deste total, 49 (21 homens e 28 mulheres) cursavam Psicologia na cidade de Niterói (RJ). Os demais 27 (17 homens e 10 mulheres) cursavam Comunicação Social - habilitação em jornalismo - na cidade de São Paulo (SP). Desta forma, dos 76 participantes, 38 eram do sexo masculino e 38 eram do sexo feminino. A seleção destes participantes foi realizada por razões práticas - os pesquisadores tinham acesso fácil a eles.

\section{Material}

Foi utilizado um inventário do tipo auto-relato sobre histórias amor, especialmente construído para esta pesquisa. Este inventário foi construído a partir dos resultados da pesquisa de Sternberg (1996), que identificou 24 tipos de histórias de amor e descreveu suas principais características. Estas histórias são as seguintes: (1) Vício, (2) Arte, (3) Negócios, (4) Colecionar, (5) Livro de Receitas, (6) Fantasia, (7) Jogos e Esportes, (8) Jardinagem, (9) Governo, (10) História, (11) Horror, (12) Casa E Comida, (13) Humor, (14) Mistério, (15) Polícia, (16) Pornografia, (17) Recuperação, (18) Religião, (19) Ciência, (20) Ficção Científica, (21) Costurar e Tricotar, (22) Teatro, (23) Viagem e (24) Guerra. Com base nas características destas histórias, apresentadas por este autor, foram elaborados 24 textos curtos - um para cada tipo de história de amor.

Após cada história foi incluída uma escala do tipo Likert, com sete opções de resposta, cuja graduação era de -3 (discordo totalmente) a +3 (concordo totalmente). (Anexo 1)
Também foram incluídas três questões que foram formuladas com os objetivos de captar aquelas histórias com as quais os participantes mais se identificavam, menos se identificavam e mais gostariam de viver. Estas questões e a instrução que as acompanhavam eram as seguintes:

Dentre as possibilidades de relacionamento lidas nestas vinte e quatro histórias, cite o número

a) da história com a qual você mais se identifica

b) da história com a qual você menos se identifica

c) da história que você mais gostaria de viver

\section{Procedimento}

Tanto o estudo piloto como a pesquisa propriamente dita foram realizadas através de aplicação coletiva em grupos de participantes.

\section{Estudo piloto}

Este estudo-piloto foi realizado para a avaliação do entendimento das histórias de amor e das instruções para responder o questionário. Este estudo foi realizado com 11 estudantes, sendo seis mulheres e cinco homens. Após a análise dos dados, as apresentações de algumas histórias foram reformuladas e, então, incluídas no instrumento definitivo.

\section{Aplicação da pesquisa}

Os participantes foram informados sobre os objetivos da pesquisa e receberam a garantia da impossibilidade de suas identificações pessoais (os questionários respondidos foram depositados em envelopes sem identificação e embaralhados, garantindo assim o sigilo sobre a identidade daqueles que os responderam). Em seguida foram instruídos para que lessem as instruções dos questionários e os respondessem.

\section{Procedimento para computação e interpretação dos dados da primeira questão - História vivencia- da no atual/último relacionamento}

Para facilitar a análise das respostas da primeira questão, as respostas a cada escala bipolar tipo Likert foram transformados em escalas unipolares de 7 pontos. Para isso foram adotadas as seguintes correspondências: $-3=1 ;-2=2 ;-1=1 ; 0=4 ;+1=5 ;+2=6$ e $+3=7$. Nestas escalas transformadas, os valores acima de 
4,00 indicavam as histórias que os participantes da pesquisa concordavam que eram próximas das descrições dos seus atuais/últimos relacionamentos amorosos. Os valores abaixo de quatro indicavam as histórias que os participantes discordavam como sendo próximas deste tipo de descrição. $\mathrm{O}$ valor 4,00 indicava histórias que os participantes não concordavam nem discordavam que eram próximas deste tipo de descrição.

Em seguida foram calculadas as médias dos escores transformados para cada uma dada história de amor. Estas médias foram calculadas, em separado, para as respostas de todos os 76 participantes, para os 38 homens e para as 38 mulheres.

Para que uma história fosse considerada próxima da descrição do atual/último relacionamento amoroso por um grupo (grupo de todos os participantes, grupo de homens ou grupo de mulheres) ela tinha, no mínimo, que ser considerada "próxima" por uma boa parte deste grupo (no mínimo ela tinha que receber a nota máxima de acordo -7 pontos - por pelo menos 44 dos 76 participantes $(7 \times 44 / 76=4,05)$ ou uma nota menor que esta, atribuída por um número maior de participantes de tal forma que esta mesma média fosse alcançada. No caso dos grupos de 38 homens e 38 mulheres as histórias, no mínimo, tinham que receber uma avaliação 7 por pelo menos 22 dos participantes ( 7 X 22 / $38=4,05$ ) ou uma avaliação menor por um número maior de participantes, de tal forma que os cálculos análogos continuassem a produzir, no mínimo, a mesma média.

Procedimento para computar e analisar os dados das três últimas questões: história mais identificada, menos identificada e mais desejada.

Para as três questões seguintes foram computadas as percentagens de participantes de cada grupo (grupo de todos os 76 participantes, grupo de homens - 38 participantes, e grupo de mulheres - 38 participantes) que optaram por cada uma das 24 histórias para responder a cada uma destas questões.

\section{RESULTADOS E DISCUSSÃO}

\section{Uso das histórias para descrever os últimos/atuais relacionamentos amorosos}

A Tabela 1 apresenta os escores médios das avaliações dos participantes que julgaram quão próximas de suas vivências era cada uma das 24 histórias de amor para descrever os seus atuais/últimos relacionamentos amorosos. Os nomes das histórias de amor aparecem na primeira coluna desta tabela, na ordem decrescente das médias das pontuações que lhes foram atribuídas por todos os 76 participantes da pesquisa. Esta tabela também mostra a média dos escores de cada história para todos os participantes (segunda coluna), para o grupo de mulheres (terceira coluna) e para o grupo de homens (quarta coluna). Estas estes escores podiam variar de 1,00 a 7,00. Os escores médios de todos os participantes variaram entre 5,51 (Polícia) e 2,83 (Costurar \& Tricotar).Os escores médios dos homens e mulheres variaram entre 5,53 (Viagem - Mulheres) e 2,71 (Polícia - Homens).

Como pode ser observado na primeira coluna do corpo Tabela 1, onze das vinte e quatro histórias foram consideradas, em média, por todos os participantes, como próximas das descrições de seus atuais/ últimos relacionamentos amorosos (obtiveram médias acima de 4,0). Estas histórias são as seguintes: 23 Viagem, 8 - Jardinagem, 21 - Costurar \& Tricotar, 10 - História, 13 - Humor, 19 - Ciência, 7 - Jogos \& Esportes, 12 - Casa \& Comida, 14 - Mistério, 6 Fantasia e 17 - Recuperação. As outras treze histórias foram consideradas, em média, não próximas deste tipo de descrição (obtiveram médias abaixo de 4,0), por estes participantes. Nenhuma história recebeu uma pontuação média que a colocasse exatamente no ponto neutro da escala de avaliação utilizada ( 4,0 pontos).

As três primeiras histórias que aparecem na coluna marginal (Viagem, Jardinagem e Costurar \& Tricotar) desta tabela receberam avaliações médias mais altas e diferenciadas: mais que 5,0 pontos. São três histórias que apresentam uma visão positiva e dinâmica do relacionamento. Estas histórias também enfatizam que o relacionamento tem que ser cuidado e pode ser moldado pelos participantes.

O fato de onze histórias terem sido consideradas próximas das descrições dos atuais/últimos relacionamentos amorosos dos participantes é coerente com as teorias modernas sobre o amoroso que afirmam que existem vários tipos de amor (Lee, 1986; Sternberg, 1986, Shaver, Hazan \& Bradshaw, 1986, por exemplo). Várias das treze histórias que não foram aprovadas para este fim talvez não devam ser descartadas como irrelevantes para este fim porque o presente estudo foi realizado apenas com um pequeno número de participantes, os quais não podem, a priori ser considerados representativos de outros grupos neste aspecto.

A inspeção dos dados mostra que quase todos os participantes atribuíram altos escores para pelo menos uma das histórias e que frequientemente cada participante atribuiu altos escores para várias histórias. $\mathrm{O}$ mesmo aconteceu com os baixos escores. Isto indica que muitas pessoas não possuem apenas uma história 
típica de amor, mas sim que seus relacionamentos têm características que se enquadram em várias destas histórias descritas por Sternberg. Ou seja, tais relacio- namentos são "mistos" quando classificados segundo estas histórias.

Tabela 1. Quanto cada história de amor era considerada próxima da descrição do atual/último relacionamento amoroso dos participantes da pesquisa

\begin{tabular}{lccc}
\hline Histórias de Amor & $\begin{array}{c}\text { Médias de pontos de } \\
\text { todos os participantes } \\
\text { (ordem decrescente) }\end{array}$ & $\begin{array}{c}\text { Médias de pontos das } \\
\text { mulheres }\end{array}$ & $\begin{array}{c}\text { Medias de pontos dos } \\
\text { homens }\end{array}$ \\
\hline 23 - Viagem & $5,51^{*}$ & 5,53 & 5,50 \\
08 - Jardinagem & 5,42 & 5,63 & 5,21 \\
21 - Costurar \& Tricotar & 5,41 & 5,56 & 5,27 \\
10 - História & 4,79 & 4,87 & 4,71 \\
13 - Humor & 4,59 & 4,79 & 4,39 \\
19 - Ciência & 4,50 & 4,26 & 4,74 \\
07 - Jogos \& Esportes & 4,24 & 3,92 & 4,55 \\
12 - Casa \& Comida & 4,24 & 4,26 & 4,21 \\
14 - Mistério & 4,09 & 4,08 & 4,10 \\
06 - Fantasia & 4,08 & 4,42 & 3,74 \\
17 - Recuperação & 4,04 & 3,71 & 4,37 \\
05 - Livro de Receitas & 3,89 & 3,71 & 4,08 \\
01 - Vício & 3,87 & 3,82 & 3,92 \\
09 - Governo & 3,82 & 3,87 & 3,76 \\
24 - Guerra & 3,72 & 3,76 & 3,68 \\
16 - Pornografia & 3,72 & 3,82 & 3,63 \\
02 - Arte & 3,66 & 3,45 & 3,87 \\
20 - Ficção Científica & 3,57 & 3,76 & 3,37 \\
11 - Horror & 3,55 & 3,61 & 3,50 \\
03 - Negócios & 3,53 & 3,53 & 3,53 \\
04 - Colecionável & 3,34 & 3,47 & 3,21 \\
18 - Religião & 3,25 & 3,11 & 3,39 \\
22 - Teatro & 3,24 & 3,39 & 3,08 \\
15 - Polícia & 2,83 & 2,95 & 2,71 \\
\hline
\end{tabular}

*As histórias que obtiveram valores médios acima de 4,00 foram consideradas próximas da descrição do atual/último relacionamento amoroso dos participantes. Aquelas com valores abaixo de 4,00 não foram consideradas próximas desta descrição.

As pontuações atribuídas pelos grupos de homens e mulheres para estas histórias foram semelhantes entre si $(r=0,89 ; 22 \mathrm{gl} ; \mathrm{p}<0,01$,$) . Apenas três da vinte$ e quatro histórias receberam avaliações médias divergentemente pelos dois sexos: as histórias Recuperação e Livro de Receitas foram aprovadas pelos homens como descritivas de seus relacionamento, mas não pelas mulheres; no caso da história Fantasia aconteceu o contrário - aprovação pelas mulheres mas não pelos homens. Esta grande semelhança entre homens e mulheres era esperada, uma vez tais histórias geralmente acontecem entre pessoas dos dois sexos e, portanto, devem ser receber descrições semelhantes por parte de ambos.

\section{Histórias de amor que os participantes mais se identificaram, menos se identificaram e que mais gostariam de viver}

Na tabela 2 são apresentadas as percentagens de participantes que optaram por cada uma das vinte e quatro histórias para responder cada uma das outras três questões que lhes foram apresentadas. A coluna marginal desta tabela mostra os títulos destas histórias. As colunas do corpo desta tabela mostram as percentagens de participantes que escolheram cada uma destas histórias para responder estas questões.

Todas as vinte e quatro histórias foram escolhidas pelo menos por um dos participantes para responder a pelo menos uma destas três questões. Ou seja, nenhuma história de amor deixou de ser escolhida como resposta para todas as três perguntas por todos os participantes. Portanto todas as 24 histórias foram relevantes para este tipo de pesquisa. 
Tabela 2. Histórias de amor que os participantes mais se identificaram, menos se identificaram e mais gostariam de viver (\%s de participantes)

\begin{tabular}{|c|c|c|c|c|c|c|c|c|c|}
\hline Histórias de amor & \multicolumn{3}{|c|}{ Mais se identificaram } & \multicolumn{3}{|c|}{ Menos se identificam } & \multicolumn{3}{|c|}{ Mais gostariam de viver } \\
\hline & Total & Homens & Mulheres & Total & Homens & Mulheres & Total & Homens & Mulheres \\
\hline 01 - Viagem & 22,4 & 23,7 & 21,1 & 0,0 & 0,0 & 0,0 & 28,9 & 34,2 & 21,1 \\
\hline 02 - Costurar \& Tricotar & 18,4 & 18,4 & 18,4 & 2,6 & 5,3 & 0,0 & 19,7 & 21,1 & 18,4 \\
\hline 06 - Jogos \& Esportes & 9,2 & 10,5 & 7,9 & 0,0 & 0,0 & 0,0 & 5,3 & 5,3 & 5,3 \\
\hline 03 - Jardinagem & 6,7 & 2,6 & 10,5 & 0,0 & 0,0 & 0,0 & 10,5 & 10,5 & 10,5 \\
\hline 07 - Humor & 6,7 & 13,6 & 0,0 & 0,0 & 0,0 & 0,0 & 1,3 & 0,0 & 2,6 \\
\hline 15 - Fantasia & 6,7 & 0,0 & 13,6 & 1,3 & 0,0 & 2,6 & 9,2 & 5,3 & 13,6 \\
\hline 05 - História & 5,3 & 7,9 & 2,6 & 1,3 & 0,0 & 2,6 & 2,6 & 2,6 & 2,6 \\
\hline 18 - Negócios & 3,9 & 2,6 & 5,3 & 5,3 & 10,5 & 0,0 & 0,0 & 0,0 & 0,0 \\
\hline 10 - Mistério & 3,9 & 2,6 & 5,3 & 1,3 & 2,6 & 0,0 & 6,7 & 5,3 & 7,9 \\
\hline 09 - Casa \& Comida & 3,9 & 7,9 & 0,0 & 2,6 & 5,3 & 0,0 & 1,3 & 2,6 & 0,0 \\
\hline 12 - Vício & 2,6 & 2,6 & 2,6 & 11,8 & 15,8 & 7,9 & 5,3 & 5,3 & 5,3 \\
\hline 04 - Ciência & 2,6 & 0,0 & 5,3 & 0,0 & 0,0 & 0,0 & 3,9 & 2,6 & 5,3 \\
\hline 21 - Ficção Científica & 2,6 & 2,6 & 2,6 & 9,2 & 7,9 & 10,5 & 0,0 & 0,0 & 0,0 \\
\hline 14 - Governo & 1,3 & 2,6 & 0,0 & 7,7 & 10,5 & 5,3 & 0,0 & 0,0 & 0,0 \\
\hline 08 - Recuperação & 1,3 & 0,0 & 2,6 & 2,6 & 0,0 & 5,3 & 1,3 & 2,6 & 0,0 \\
\hline 20 - Religião & 1,3 & 2,6 & 0,0 & 11,1 & 5,3 & 15,8 & 0,0 & 0,0 & 0,0 \\
\hline 22 - Teatro & 1,3 & 0,0 & 2,6 & 5,3 & 2,6 & 7,9 & 0,0 & 0,0 & 0,0 \\
\hline 13 - Arte & 0,0 & 0,0 & 0,0 & 0,0 & 0,0 & 0,0 & 1,3 & 0,0 & 2,6 \\
\hline 22 - Colecionável & 0,0 & 0,0 & 0,0 & 9,2 & 7,9 & 10,5 & 1,3 & 2,6 & 0,0 \\
\hline 11 - Livro de Receitas & 0,0 & 0,0 & 0,0 & 0,0 & 0,0 & 0,0 & 1,3 & 0,0 & 2,6 \\
\hline 16 - Guerra & 0,0 & 0,0 & 0,0 & 9,2 & 10,5 & 7,9 & 0,0 & 0,0 & 0,0 \\
\hline 17 - Pornografia & 0,0 & 0,0 & 0,0 & 7,9 & 5,3 & 10,5 & 0,0 & 0,0 & 0,0 \\
\hline 19 - Horror & 0,0 & 0,0 & 0,0 & 6,7 & 2,6 & 10,5 & 0,0 & 0,0 & 0,0 \\
\hline 24 - Polícia & 0,0 & 0,0 & 0,0 & 5,3 & 7,9 & 2,6 & 0,0 & 0,0 & 0,0 \\
\hline
\end{tabular}

As três primeiras colunas do corpo da Tabela 2 apresentam as percentagens de participantes que escolheram cada uma das histórias para responder a questão "Qual história que você mais se identifica?" A primeira destas colunas apresenta as percentagens de todos os 76 participantes, a segunda coluna as percentagens dos homens e a terceira coluna as percentagens das mulheres.

Dezessete das histórias de amor foram escolhidas por pelo menos um dos participantes como aquela que ele mais se identificava. Estas histórias são as seguintes: 1 - Viagem, 2 - Costurar \& Tricotar, 6 - Jogos \& Esportes, 3 - Jardinagem, 7 - Humor, 15 - Fantasia, 5 - História, 18 - Negócios, 10 - Mistério, 9 - Casa \& Comida, 12 - Vício, 4 - Ciência, 21 -Ficção Científica, 14 - Governo, 8 - Recuperação, 20 - Religião e 22 - Teatro.

As três histórias mais escolhidas para responder esta questão foram as seguintes: Viagem $(22,4 \%)$ e Costurar \& Tricotar $(18,4 \%)$ e Jogos \& Esportes $(9,2 \%)$. As duas primeiras destas questões são as mesmas que os participantes, ao responder a questão anterior, afirmaram serem as mais próximas das descrições dos seus relacionamentos atuais/últimos. A história Jogos \& Esportes também obteve um alto escore na questão anterior. Elas apresentam visões positivas, dinâmicas e construtivas dos relacionamentos, segundo a qual os parceiros estão crescendo juntos (Viagem) e o relacionamento pode ser moldado para satisfazê-los (Costurar \& Tricotar). A terceira destas histórias enfatiza o lado divertido e prazeroso do relacionamento.

As sete histórias que não foram escolhidas por nenhum participante para responder esta questão foram as seguintes: Arte, Colecionável, Livro de Receitas, Guerra, Pornografia, Horror e Polícia. Estas histórias são aquelas que descrevem relacionamentos que são considerados pela nossa cultura como socialmente negativos: possuem características socialmente condenáveis (Colecionável), produzem sofrimento e estresse (Guerra), são ações condenadas pelos padrões culturais (Pornografia,), apresentam o relacionamento amoroso de forma superficial (Livro de Receitas).

As percentagens respostas de homens e mulheres apresentaram uma correlação de magnitude moderada, mas estatisticamente significante $(0,67 ; 22 \mathrm{gl}, \mathrm{p}<0,01)$. Homens e mulheres, portanto, apresentaram uma dose média de semelhança quando usaram estas histórias 
para descrever os tipos de relacionamentos que mais se identificam. As percentagens de homens e mulheres foram idênticas para algumas das histórias (por exemplo, Costurar \&Tricotar e Viagem) e diferentes para outras (por exemplo, Humor e Fantasia). Estas semelhanças e diferenças nas formas de responder dos dois sexos provavelmente refletem semelhanças e diferenças nos padrões culturais que guiaram suas educações.

\section{História que os participantes menos se identificaram}

As quarta, quinta e sexta colunas do corpo da Tabela 2 mostram as percentagens de participantes (todos os participantes, percentagens dos homens e percentagens das mulheres, respectivamente) que apontaram cada uma das histórias como aquela que menos se identificaram.

Dezessete das vinte e quatro histórias foram apontadas por pelo menos um dos participantes como aquela que menos se identificava. Estas histórias são as seguintes: 2 - Costurar \& Tricotar, 15 - Fantasia, 5 - História, 18 - Negócios, 10 - Mistério, 9 - Casa \& Comida, 12 - Vício, 21 - Ficção científica, 14 - Governo, 8 - Recuperação, 20 - Religião, 22 - Teatro, 22 - Colecionável, 16 - Guerra, 17 - Pornografia, 19 - Horror e 24 - Polícia. Há, portanto, uma grande variação entre as pessoas nas suas escolhas das histórias para responder este tipo de questão. Elas diferem bastante entre si não apenas nas histórias de amor com as quais se identificam como também naquelas que percebem mais distantes de si.

Dentre estas dezessete histórias menos identificadas, aquelas que obtiveram as maiores frequiências de escolha foram: Vício $(11,8 \%)$, Religião $(11,4 \%)$, Colecionável $(9,2 \%)$, Ficção Científica $(9,2 \%)$ e Guerra $(9,2 \%)$. Estas histórias apresentam o relacionamento amoroso como dependência entre os parceiros (Vício) devoção exagerada ao parceiro (Religião), permeado pela estranheza e incompreensão da forma de ser do parceiro (Ficção Científica) ou como uma batalha sem fim (Conflito).

Quatro histórias se destacam por só terem sido escolhidas para responder esta questão - nenhum dos participantes citou-as como aquelas que mais se identificava ou como aquela que mais gostaria de viver. Estas histórias são as seguintes: Guerra, Pornografia, Horror e Polícia. Todas estas quatro histórias também foram apontadas, na primeira questão desta pesquisa, dentre aquelas que os participantes discordavam como próximas das descrições de seus atuais/últimos relacionamentos.
Sete histórias não foram citadas por nenhum dos participantes como aquela que menos se identificava: Viagem, Jogos \& Esportes, Jardinagem, Humor, Ciência, Arte e Livro de Receitas. Estas histórias, de uma forma geral, tendem a ser aquelas que melhor descrevem os relacionamentos amorosos atuais/últimos, as histórias que os participantes mais se identificaram ou as histórias que gostariam de viver.

É possível, portanto, que as pessoas não estabeleçam um relacionamento amoroso quando a história que ocorreria com o parceiro seria uma destas que ele não se identifique ou que abandonem tal relacionamento quando este tipo de história começa a surgir.

Foi constatada uma semelhança fraca, mas estatisticamente significante, nas percentagens de homens e mulheres que escolheram cada uma das vinte e quatro histórias como aquelas que menos se identificam $(\mathrm{r}=$ $0,43 ; 36 \mathrm{gl}, \mathrm{p}<0,05)$. Várias histórias foram escolhidas para esta finalidade por percentagens idênticas ou semelhantes de homens e mulheres (ver a Tabela 2). Outras histórias foram escolhidas por percentagens bem diferentes de homens e mulheres. A história Negócios foi a que apresentou a maior diferença de escolhas entre homens e mulheres (homens - 10,5\%, mulheres $-0,0 \%$ ) de indicações como a história que menos se identificavam. Nesta história o dinheiro é explicitamente o centro do poder e do relacionamento. $\mathrm{O}$ fato de mais homens do que mulheres apontarem esta história como a que menos se identificavam está de acordo com achados que indicam que as mulheres são mais pragmáticas do que eles (Hendrick \& Hendrick, 1992).

\section{Histórias que os participantes mais gostariam de viver}

A sétima, oitava e nona colunas do corpo da Tabela 2 (todos os participantes, homens e mulheres, respectivamente) mostram as percentagens de participantes que apontaram cada uma das histórias de amor como aquela que mais gostariam de viver. Quinze histórias foram escolhidas por pelo menos um dos participantes como aquela que mais gostaria de viver. Estas histórias são as seguintes: 1 - Viagem, 2 Costurar \& Tricotar, 6 - Jogos \& Esportes, 3 - Jardinagem, 7 - Humor, 15 - Fantasia, 5 - História, 10 Mistério, 9 - Casa \& Comida, 12 - Vício, 4 - Ciência, 8 - Recuperação, 13 - Arte, 22 - Colecionável, 11 Livro de Receitas.

As histórias mais escolhidas por todos os participantes para responder esta questão foram as seguintes: Viagem (28,9\%) e Costurar e Tricotar (19,7\%). Estas duas histórias também foram as que receberam os 
maiores escores como as que melhor descreviam os relacionamentos amorosos atuais/(último e também foram as mais escolhidas como aquelas que os participantes mais se identificam. As percentagens de escolha das duas primeiras destas histórias se destacam das percentagens de escolha das demais. Consideradas em conjunto estas duas histórias foram escolhidas por 48,6\% dos participantes. As características destas duas histórias já foram apresentadas acima, no tópico histórias que os participantes mais se identificaram.

As percentagens de homens e mulheres que escolheram cada uma das vinte e quatro histórias de amor são muito semelhantes $(r=0,92,22 \mathrm{gl}, \mathrm{p}<0,01)$. Este alto grau de concordância indica que percentagens semelhantes de homens e mulheres que participaram desta pesquisa querem viver as mesmas histórias. Caso este fenômeno também aconteça na população isto facilitaria encontrar alguém do sexo oposto que queira viver a mesma história de amor que quem está procurando, sem grandes concorrências neste setor, já que as procuras estão equilibradas com as ofertas. Querer viver a mesma história de amor e desempenhar papéis complementares na mesma história também é um requisito fundamental para que o relacionamento amoroso dê certo (Sternberg, 1998).

Nove histórias não foram citadas por nenhum dos participantes como aquela que mais gostariam de viver. Estas histórias são as seguintes: 16 - Guerra, 17 Pornografia, 19 - Horror, 24 - Polícia, 20 - Religião, 22 - Teatro, 21-Ficção Científica, 14 - Governo, 18 Negócios. Estas histórias provavelmente não foram escolhidas como ideais porque tratam o amor de uma forma não aprovada pelos valores sociais deste grupo de participantes. Elas vêem o relacionamento de forma muito comercial (Negócios), degradante (Pornografia), medo do parceiro (Horror), desconfiança (Polícia), devoção exagerada (Religião), representada (Teatro), estranha (Ficção Científica), hierárquica (Governo), ou guiada pelo dinheiro (Negócios).

A história que as pessoas mais gostariam de viver provavelmente servem de parâmetro para suas satisfações com as histórias que estão vivendo em seus relacionamentos reais. É claro que a viver a história que mais gostaria não é uma garantia de satisfação. Uma história pode ter se tornado desejável para uma pessoa porque ela foi exposta a literatura, tem percepções distorcidas, problemas psicológicos etc. Ao conseguir viver a história que idealizaram muitos poderão ficar decepcionados.

Por outro lado as histórias mais desejáveis pelo grupo como um todo devem ter passado por testes culturais, o que propicia uma certa segurança que elas têm uma chance maior de produzir um relacionamento feliz.

É mais seguro concluir que aqueles que vivenciam e/ou se identificam com histórias diferentes daquelas que mais gostariam de viver apresentam uma certa frustração (Rusbult \& Buunk, 1993). É menos seguro concluir que viver e se identificar com as histórias que mais gostariam traz a satisfação. Muitos ideais podem ser irrealísticos e até mesmo perigosos

\section{Relações entre as histórias os participantes consideraram mais descritivas do relacionamento atual/último, mais se identificam, menos se identificam e mais gostariam de viver}

Todas as 24 histórias descritas por Sternberg (1996) foram selecionadas pelos participantes da pesquisa como apropriadas para responder a pelo menos uma das quatro tarefas que realizaram: (a) avaliar quanto cada uma das 24 histórias mais se aproximavam de relacionamentos amoroso atuais/último era obrigatório considera todas as histórias). (b) identificar as histórias de amor que mais se identificam, (c) identificar as histórias de amor que menos se identificam e (d) identificar as histórias que mais desejariam viver.

As onze histórias que foram aprovadas na tarefa (a) acima também foram selecionadas como respostas nas tarefas (b) e (d) acima. Estas histórias são as seguintes: 23 - Viagem, 8 - Jardinagem, 21 - Costurar \& Tricotar, 10 - História, 13 - Humor, 19 - Ciência, 7 Jogos \& Esportes, 12 - Casa \& Comida, 14 - Mistério, 6 - Fantasia e 17 - Recuperação. Duas destas onze histórias foram relativamente mais utilizadas do que as outras nestas três tarefas: Viagem e Costurar \& Tricotar. Em conjunto, estas duas histórias: receberam um alto escore como aquelas que mais se aproximavam das descrições dos relacionamentos amorosos atuais/últimos dos participantes; foram apontadas por 40,8\% dos participantes como aquelas que eles mais se identificavam; foram apontadas por $48,6 \%$ dos participantes como aquelas que eles mais gostariam de viver. Estas duas histórias foram apontadas por apenas dois dos 76 participantes na tarefa (c) como aquelas eles que "menos se identificavam", o que corrobora este tipo de uso, já que esta tarefa era "negativa".

As outras 13 histórias (5 - Livro de Receitas, 1 - Vício, 9 - Governo, 24 - Guerra, 16 - Pornografia, 2 - Arte, 20 - Ficção Científica, 11 - Horror, 3 - Negócios, 4 - Colecionável, 18 - Religião, 22 - Teatro, 15 - Polícia) foram relativamente pouco utilizadas nestas três tarefas: foram rejeitadas, em 
média, como descritivas das vivências dos participantes (aquelas que obtiveram médias inferiores a 4,0 nas descrições dos relacionamentos atuais/últimos). Estas histórias também foram muito pouco apontadas como a "história que mais me identifico" $(10,4 \%$ de todos os participantes) e foram muito pouco apontadas como aquela que "mais gostariam de viver" $(9,1 \%$ de todos os participantes). Por outro lado, estas treze histórias foram consideras como a "que menos identifico" por 74,2\% dos participantes. Estas histórias são negativas, pouco prazerosas, estressantes, conflituosas, os parceiros ou pelo menos um deles trata o outro de forma desigual e impessoal não exclusiva.

Grande parte dos participantes enfatizaram apenas duas histórias nas suas respostas das tarefas (a), (b) e (d): Viagem e Costurar \& Tricotar . Estas duas histórias receberam escores médios acima de 5,0 pontos por parte de todos os participantes que julgaram a adequação das 24 histórias para descrever seus relacionamentos atuais/últimos; elas foram escolhidas por $40,8 \%$ dos participantes como aquelas que mais se identificam e por $48,6 \%$ dos participantes como aquelas que mais gostariam de viver. Estas mesmas duas histórias atraíram poucas respostas da tarefa "negativa" - história que menos se identificam - de apenas 2,6\% dos participantes. Portanto estas duas histórias são as mais relevantes para descrever os aspectos positivos das histórias de amor.

\section{Correlações entre as histórias apontadas como respostas para as quatro tarefas pelo grupo de todos os participantes}

Foram constatadas várias similaridades e algumas dissimilaridades nos usos que os participantes da pesquisa fizeram das histórias de amor para responder as quatro tarefas. As principais destas similaridades e dissimilaridades foram as seguintes:

Grande dose de similaridade entre os escores que os participantes atribuíram as histórias de amor como adequadas para descreveram os seus relacionamentos amorosos atuais/últimos e as percentagens de participantes que as escolheram como aquelas que mais se identificam $(\mathrm{r}=0,88,22 \mathrm{gl}, \mathrm{p}<0,01)$. Isto indica que os participantes tendem a viver em seus relacionamentos aquelas histórias que mais se identificam.

Uma dose moderada de similaridade $(\mathrm{r}=0,73,22 \mathrm{gl}$, $\mathrm{p}<0,01)$ entre os escores que os participantes atribuíram às histórias como adequadas para descrever os seus atuais/últimos e as percentagens de participantes que as escolheram como as que mais gostariam de viver. Isto indica que as histórias de amor que os par- ticipantes estão vivendo nos seus relacionamentos amorosos atuais/últimos se parecem apenas moderadamente com aquelas histórias que eles mais gostariam de viver.

Uma relação fraca e inversa, mas estatisticamente significante $(\mathrm{r}=-0,50,22 \mathrm{gl}, \mathrm{p}<0,05)$ entre as histórias que os participantes consideraram como descritivas de seus relacionamentos amorosos atuais/últimos e as percentagens de participantes que identificaram estas histórias como as que menos gostariam de viver. Isto indica que os participantes tenderam a não viver as histórias que menos se identificam, mas que esta tendência é fraca.

Uma forte dose de similaridade $(\mathrm{r}=0,93,22 \mathrm{gl}$, $\mathrm{p}<0,01)$ entre as percentagens de participantes que escolheram cada histórias como aquela que mais se identificavam e as percentagens de participantes que escolheram as histórias como aquelas que mais gostariam de viver. Isto indica que as histórias de amor que a maior parte dos participantes se identificaram tendem a ser também aquelas histórias que a maior percentagem de participantes consideram ideais.

Uma fraca dose de dissimilaridade, mas estaticamente significante $(r=-0,44,22 \mathrm{gl}, \mathrm{p}<0,05)$ entre as percentagens de participantes que escolheram cada história como as que mais se identificaram e as percentagens de participantes que escolheram as histórias como as que menos se identificaram. Isto indica que estas histórias não são antagônicas. Aquelas que mais se identificam não são necessariamente o contrário daquelas que menos se identificam. Isto aconteceu porque quando um participante escolheu uma história como aquela que mais se identificava outro participante poderia escolher a mesma história como aquela que menos se identifica. Isto indica que as pessoas podem ser semelhantes ou diferentes e até mesmo opostas quando se trata da identificação com estas histórias. Esta conclusão é reforçada pela constatação da ausência de correlação estatisticamente significante entre as percentagens de escolha das histórias que os participantes menos se identificaram com as percentagens de escolha das histórias que eles mais gostariam de viver $(r=-0,40,22 \mathrm{gl}, \mathrm{p}>0,05)$.

Estes resultados, considerados em conjunto, indicam que aquelas histórias mais vividas atualmente/último relacionamento são consideradas satisfatórias pelos participantes. Existem pelo menos duas hipóteses que podem explicar esta visão positiva: (1) as pessoas evitam viver histórias que não se identificam e que não são aquelas que gostariam de viver e (2) as pessoas tentem a ver as histórias que vivem/viveram de uma forma idealizada (efeito "gatekeeper") ou 
tentem a ver seus parceiros de forma melhor do que os amigos (Rusbult \& Buunk,1993).

As magnitudes destas correlações indicam que as histórias que melhor descrevem os relacionamentos amorosos atuais/últimos dos participantes são mais similares às histórias que elas se identificam do que às histórias que elas consideram ideais. Por outro lado, estas correlações também sugerem que as pessoas são otimistas sobre elas próprias: tentem a ver as histórias de amor com as quais se identificam como próximas daquelas que gostariam de viver.

Todas as discrepâncias individuais ou diádicas entre estes três de histórias provavelmente são produtoras de problemas. As discrepâncias possíveis são as seguintes: individuais - viver uma história que não se identifica (por exemplo, ser romântico e estar vivendo uma história baseada na amizade), querer viver uma história que não se identifica (seria como querer ser alto, mas ser baixo), viver e se identificar com uma história que não é aquela que gostaria de viver; diádicas - viver, se identificar ou querer viver uma história muito diferente daquela que agrada o parceiro amoroso.

As discrepâncias entre as histórias de amor que as pessoas vivem e as histórias que elas mais se identificam ou mais gostariam de viver provavelmente estão relacionadas com suas satisfações e com as durações de seus relacionamentos (Rusbult \& Bunk, 1993). Quando as pessoas percebem este tipo de discrepância é possível que elas acreditem que o a maior fonte do problema está na história que estão vivendo, uma vez que aquelas histórias com as quais mais se identificam são bem próximas das histórias que gostariam de viver. Uma solução para este problema seria arranjar outro parceiro para viver uma história mais próxima daquela que se identifica a qual é também bem próxima da história que mais gostaria de viver. Em certos casos, no entanto, a solução pode estar em tentar modificar a história que uma pessoa mais se identifica ou a história que ela mais gostaria de viver. Este tipo de sugestão parece o mais indicado principalmente naqueles casos que estas histórias tem um enredo de violência e conflito.

Os contrastes entre estas preferências e rejeições podem ajudar a elucidar uma série de conflitos entre casais que aparentam viver histórias semelhantes, mas que com o decorrer do relacionamento vivem ambigüidades que na prática demonstram ser empecilhos significativos e, às vezes, insuperáveis para o relacionamento. Por exemplo, este é o caso da história do tipo fantasia, com alta eleição entre o público feminino, que não foi escolhida por nenhum dos homens pesquisados como a que mais se identificaram (embora dois deles a escolheram como a que mais gostariam de viver). As muitas semelhanças e as poucas diferenças encontradas entre os gêneros devem ser aprofundadas em pesquisas futuras, pois estas táticas diferentes que os gêneros usam para tentar administrar a relação podem se revelar importantes para o êxito do aconselhamento e da condução dos relacionamentos (Gottman \& Notarius, 2002).

\section{Sugestões para pesquisas futuras}

Nas três últimas questões, nas quais os participantes são obrigados a escolher uma das histórias de amor como resposta, é aconselhável a inclusão de uma opção "nenhuma das anteriores". No caso da presente pesquisa, onde este tipo de opção não estava disponível, é possível que muitos tenham escolhido a história que mais se aproximava daquilo que se passava com eles, mesmo naqueles casos onde nenhuma história representava isso direito. Esta falha, no entanto, não comprometeu as conclusões desta pesquisa porque no primeiro questionário ("história que melhor representava o amor atual/último") havia a opção de responder negativamente sobre a representatividade de todas as histórias. Como a inspeção visual dos dados desta questão mostra que quase todos os participantes atribuíram um alto escore para pelo menos uma das histórias e os escores médios dos participantes para esta questão apresentam uma boa correlação com aqueles das últimas três questões isto, em uma certa medida, reforça a crença de que as histórias escolhidas nestas questões são realmente úteis para responder tais questões.

É necessário interpretar com cautela as correlações apresentadas neste artigo uma vez que elas foram calculadas com base nas percentagens de participantes que escolheram cada história de amor nas últimas três tarefas experimentais e nas pontuações recebidas pelas histórias nos julgamento de suas adequações para descrever os relacionamentos atuais/últimos dos participantes. Tais correlações, mesmo quando muito fortes não asseguram que foram os mesmos participantes que contribuíram para as covariações observadas. Por exemplo, mesmo que a correlação entre percentagens de pessoas que se identificam com as histórias e aqueles que mais gostariam de vivê-las fosse 1, não seria seguro acreditar que foram as mesmas pessoas que se identificaram com uma dada história são aquelas que mais gostaria de vivê-la.

É também necessário que esta pesquisa seja replicada com outros participantes, uma vez que estes resultados podem não se sustentar para pessoas com outras qualificações. 


\section{CONCLUSÕES}

Este estudo teve como objetivo a identificação das histórias de amor mais apropriadas para descrever os relacionamentos amorosos dos participantes, aquelas que eles mais se identificavam, aquelas que eles menos se identificavam e aquelas que eles mais gostariam de viver. O segundo objetivo era verificar se havia relação entre estes tipos de histórias. Foram utilizadas para este fim vinte e quatro histórias de amor descritas por Sternberg (1996). Foram identificadas onze destas histórias para descrever os relacionamentos amorosos atuais/últimos dos participantes, dezessete histórias que eles mais se identificaram, dezessete histórias que eles menos se identificam e quinze histórias que mais gostariam de viver.

Um ponto importante das histórias identificadas por Sternberg (1996), com seus papéis complementares e interdependentes, é o grande potencial de realização ou de conflito entre as expectativas de cada gênero quando formam parcerias amorosas. É o que se reflete na questão sobre as histórias com que homens e mulheres menos se identificaram.

\section{Anexo 1
INFORMAÇÕES DEMOGRÁFICAS E HISTÓRIAS DE AMOR UTILIZADAS NESTA PESQUISA}

\section{Informações demográficas sobre os participantes}

Dados de Identificação:

Idade:

Sexo:Masculino( ) Feminino( )

Estado Civil: Solteiro ( ) Casado ( ) Separado ( ) Unido Consensualmente ( ) Viúvo ( )

Instruções para identificar o tipo de história vivenciada no atual ou no último (para aqueles que não estão se relacionando atualmente) relacionamento.

\section{Instruções}

Os dados permanecerão em absoluto sigilo e só serão utilizados para fins acadêmicos.

Neste questionário estão relacionadas 24 diferentes histórias de amor. Considere o seu relacionamento amoroso atual ou 0 último e avalie o quanto cada uma dessas histórias se aproxima da sua vivência. Para isso, utilize a escala proposta. Lembre-se que a melhor resposta é aquela que mais representa a sua opinião sobre cada uma delas, e assim não há respostas erradas, nem melhores que as outras.

Significado dos pontos das escalas de resposta

-3 Discordo Totalmente

-2 Discordo Moderadamente

-1 Discordo Levemente

0 Não Discordo e Nem Concordo

+1 Concordo Levemente

+2 Concordo Moderadamente

+3 Concordo Totalmente

\section{Como é seu relacionamento?}

1. Um relacionamento intenso com sentimentos de ansiedade de perder o parceiro e desejo de ficar o mais possível agarrado a ele. Tenho pensamentos do tipo "eu não poderia viver sem ele".

\begin{tabular}{lllllll}
\hline-3 & -2 & -1 & 0 & +1 & +2 & +3
\end{tabular}

2. Um relacionamento com forte atração física, com muita importância à aparência do meu parceiro, que sempre deve parecer bem. Tenho pensamentos do tipo "esse é o parceiro mais bonito que eu poderia encontrar".

\begin{tabular}{lllllll}
\hline-3 & -2 & -1 & 0 & +1 & +2 & +3
\end{tabular}

3. Um relacionamento com papéis e tarefas muito bem definidos, onde cada parceiro tem 0 seu lugar. $O$ dinheiro desempenha um papel importante e tem a ver com poder. Tenho pensamentos do tipo "estamos nesse negócio juntos".

\begin{tabular}{lllllll}
\hline-3 & -2 & -1 & 0 & +1 & +2 & +3
\end{tabular}

4. Um relacionamento no qual o parceiro se adequa como uma luva ao meu esquema. Há tendência e o gosto de ter múltiplos parceiros ao mesmo tempo, cada um deles preenchendo papéis um pouco diferentes uns dos outros. Tenho pensamentos do tipo "essas diferentes pessoas preenchem minhas diversas necessidades".

\begin{tabular}{lllllll}
\hline-3 & -2 & -1 & 0 & +1 & +2 & +3
\end{tabular}

5. Um relacionamento no qual parece haver uma receita de como agir e/ou de que coisas fazer. Quando essa receita é cumprida, a relação vai bem. Caso contrário, pode desandar. Tenho pensamentos do tipo "damos certo porque nós sempre..."

\footnotetext{
\begin{tabular}{lllllll}
\hline-3 & -2 & -1 & 0 & +1 & +2 & +3
\end{tabular}

Interação em Psicologia, Curitiba, jul./dez. 2005, (9)2, p. 295-309
} 
6. Um relacionamento no qual sinto-me como se tivesse encontrado meu príncipe (princesa) encantado (a). Tenho pensamentos do tipo "ele (ela) é um sonho tornado realidade".

\begin{tabular}{lllllll}
\hline-3 & -2 & -1 & 0 & +1 & +2 & +3
\end{tabular}

7. Um relacionamento no qual o amor é um jogo empolgante, divertido e alegre. Afinal, as coisas nem sempre podem ser levadas muito a sério. Tenho pensamentos do tipo "jogo para curtir".

\begin{tabular}{lllllll}
\hline-3 & -2 & -1 & 0 & +1 & +2 & +3
\end{tabular}

8. Um relacionamento que precisa ser bem nutrido, como uma planta. Tenho pensamentos do tipo "eu trato do meu relacionamento com quem cuida de uma flor".

\begin{tabular}{lllllll}
\hline-3 & -2 & -1 & 0 & +1 & +2 & +3
\end{tabular}

9. Um relacionamento no qual o poder pode ser exercido por um dos parceiros ou compartilhado. Há um parceiro que controla e outro é controlado. Tenho pensamentos do tipo "nessa relação, eu deveria tomar as decisões" ou "nessa relação, meu parceiro deveria tomar as decisões".

\begin{tabular}{lllllll}
\hline-3 & -2 & -1 & 0 & +1 & +2 & +3
\end{tabular}

10. Um relacionamento no qual os bons e os maus momentos estão vivos na memória. Há muitas lembranças e recordações, tais como fotos, gravações, souvenires. Tenho pensamentos do tipo "nosso passado tornou-se parte de nós".

\begin{tabular}{lllllll}
\hline-3 & -2 & -1 & 0 & +1 & +2 & +3
\end{tabular}

11. Um relacionamento que se torna interessante quando sinto um pouco de medo do meu parceiro, ou vice-versa. Tenho pensamentos do tipo "ele está com receio de mim e gosto que seja assim" ou "estou com receio dele e sinto um gostinho bom nisso".

\begin{tabular}{lllllll}
\hline-3 & -2 & -1 & 0 & +1 & +2 & +3
\end{tabular}

12. Um relacionamento no qual o centro é o lar e as coisas relacionadas a ele. A ênfase está em ter um ambiente confortável em casa. Tenho pensamentos do tipo "a casa é a coisa principal em nossas vidas" ou "lar, doce lar".

\begin{tabular}{lllllll}
\hline-3 & -2 & -1 & 0 & +1 & +2 & +3
\end{tabular}

13. Um relacionamento no qual há senso de humor e o reconhecimento de que a vida tem um lado engraçado. Eventualmente, o humor pode mascarar relações tensas. Há frases e piadinhas do tipo "minha mulher fugiu com meu melhor amigo e estou sentindo falta dele".

\begin{tabular}{lllllll}
\hline-3 & -2 & -1 & 0 & +1 & +2 & +3
\end{tabular}

14. Um relacionamento no qual há um quê de mistério, uma necessidade constante de saber mais sobre o parceiro, um clima de segredo no ar. Pensamentos do tipo "tenho segredos e gosto que seja assim, isso faz com que ele fique tentando adivinhar".

\begin{tabular}{lllllll}
\hline-3 & -2 & -1 & 0 & +1 & +2 & +3
\end{tabular}

15. Um relacionamento no qual há necessidade de manter rédeas curtas no parceiro, para ter certeza que ele anda na linha. Há um forte interesse na vida e nas atividades do parceiro. Pensamentos do tipo "quero saber tudo o que esse sujeito faz".

\begin{tabular}{lllllll}
\hline-3 & -2 & -1 & 0 & +1 & +2 & +3
\end{tabular}

16. Um relacionamento no qual o amor é visto como algo permissivo, no qual um parceiro é degradado ou degrada o outro. A emoção da relação está nessa degradação. Tenho pensamentos do tipo "libertar-se das amarras" ou "entre quatro paredes vale tudo".

\begin{tabular}{lllllll}
\hline-3 & -2 & -1 & 0 & +1 & +2 & +3
\end{tabular}

17. Um relacionamento no qual há a consciência de ser um sobrevivente, a certeza que depois dos traumas e sofrimentos passados a pessoa pode enfrentar praticamente qualquer situação. Tenho pensamentos do tipo "eu passei pelo pão que o diabo amassou e estou pronto para começar de novo".

\begin{tabular}{lllllll}
\hline-3 & -2 & -1 & 0 & +1 & +2 & +3
\end{tabular}

18. Um relacionamento no qual o amor é visto como uma religião, com devoção intensa ao parceiro. Tenho pensamentos do tipo "o amor é como se fosse a minha salvação".

\begin{tabular}{lllllll}
\hline-3 & -2 & -1 & 0 & +1 & +2 & +3
\end{tabular}

19. Um relacionamento no qual as coisas podem ser compreendidas, analisadas e dissecadas, como qualquer outro fenômeno da natureza. Procurar compreender com objetividade 0 parceiro e a relação. Tenho pensamentos do tipo "eu sei exatamente como ele vai responder se eu..."

\begin{tabular}{lllllll}
\hline-3 & -2 & -1 & 0 & +1 & +2 & +3
\end{tabular}

20. Um relacionamento no qual há um sentimento de que o parceiro é como um alienígena - incompreensível e muito es- 
tranho. Pensamentos do tipo "esse cara deve ter vindo de outro planeta", "caramba! Isso não faz nenhum sentido..."

\begin{tabular}{lllllll}
\hline-3 & -2 & -1 & 0 & +1 & +2 & +3
\end{tabular}

21. Um relacionamento no qual o amor é aquilo que você quiser fazer com ele, algo que você molda como for melhor, é questão de usar a criatividade. Cada relacionamento é único. Tenho pensamentos do tipo "criamos nossa relação de um jeito muito pessoal".

\begin{tabular}{lllllll}
\hline-3 & -2 & -1 & 0 & +1 & +2 & +3
\end{tabular}

22. Um relacionamento no qual parece haver um roteiro prédefinido, com atos, cenas e falas previsíveis. Há algo de dramático no ar. Às vezes a pessoa sente como se não estivesse se comportando naturalmente e sim interpretando um papel. Pensamentos do tipo "a próxima fala é..."

\begin{tabular}{lllllll}
\hline-3 & -2 & -1 & 0 & +1 & +2 & +3
\end{tabular}

23. Um relacionamento no qual há uma sensação de grande jornada conjunta, uma viagem em conjunto. Planeja-se para 0 amanhã, há um pensamento voltado para o futuro. Tenho pensamentos do tipo "nós estamos sempre crescendo juntos".

\begin{tabular}{lllllll}
\hline-3 & -2 & -1 & 0 & +1 & +2 & +3
\end{tabular}

24. Um relacionamento no qual o amor é uma guerra, uma série de batalhas sem fim. $O$ conflito parece ser intenso e mantémse ao longo do tempo. Tenho pensamentos do tipo "estou pronto pra lutar pelo que acho certo".
Identificação das histórias de amor

(Estas identificações não foram oferecidas para os participantes)
História 1: vício.
História 2: arte.
História 3: negócios.
História 4: colecionável.
História 5: livro de receitas.
História 6: fantasia.
História 7: jogos e esportes.
História 8: jardinagem.
História 9: governo.
História 10: história.
História 11: horror.
História 12: casa e comida.
História 13: humor.
História 14: mistério.
História 15: polícia.
História 16: pornografia.
História 17: recuperação.
História 18: religião.
História 19: ciência.
História 20: ficção científica.
História 21: costurar e tricotar.
História 22: teatro.
História 23: viagem.
História 24: guerra.

\section{Anexo 2
INSTRUÇÕES PARA RESPONDER AS TRÊS ÚLTIMAS QUESTÕES}

Considere novamente as histórias que você já leu e responda as três questões abaixo. A melhor resposta é simplesmente aquela que representa sua opinião sobre cada uma das histórias apresentadas.

Os dados pessoais permanecerão em absoluto sigilo e só serão utilizados para fins acadêmicos.

Desde já, agradecemos sua preciosa colaboração!

\section{Questões}

Dentre as histórias lidas, cite o número de uma, e apenas uma:

a) História com a qual você mais se identifica

b) História com a qual você menos se identifica

c) História que você mais gostaria de viver 


\section{REFERÊNCIAS}

Amélio, A. (2001). O mapa do amor: tudo o que você queria saber sobre o amor e ninguém sabia responder. São Paulo: Editora Gente.

Badinter, E. (1985). Um amor conquistado: o mito do amor materno. Rio de janeIro: Nova Fronteira (Original publicado em 1980).

Bowlby, J. (1989). Uma base segura: aplicações clínicas para a teoria do apego. Porto Alegre: Artes Médicas.

Buss, M. D. (1994). The evolution of desire. New York, Basic Books.

Hendrick, S. S. \& Hendrick, C. (1992) Romantic love. Newbury Park: Sage Publications.

Gottman, J. M. \& Notarius, C. I. (2002). Marital Research in the $20^{\text {th }}$ Century and a Research agenda for the 21th Century. Family Process, 41(2), 158-197.

Lee, J. A. (1988). Love-Stiles. Em R. J. Sternberg \& M. L. Barnes (Orgs.). The psychology of love (pp. 39-67). New Haven: Yale University Press.

Lemos, P. (1994). Educação afetiva: porque as pessoas sofrem no amor. ( $8^{\mathrm{a}}$ ed.). São Paulo: Lemos Editorial.

Levine, S. B. (1988). Intrapsychic and individual aspects of sexual desire. Em S. R. Leibrum \& R. C. Rosen (Orgs.), Sexual desire disorders (pp. 2143). New York, The Guilford Press.

Macfarlane, A. (1989). A cultura do capitalismo. Zahar: Rio de Janeiro.
Money, J. (1986). Love maps: clinical concepts of sexual/erotic health and pathology. Paraphilia, and gender transposition in childhood, adolescence and maturity. New York: Irvington Publishers.

Pinsof, W. M. (2002). The death of "Till death us do part": The transformation of pair-bonding in the $20^{\text {th }}$ Century. Family Process, 41(2), 135-157.

Rubin, Z. (1970). Measurement of romantic love. Journal of Personality and Social Psychology, 16, 265-273.

Rusbult, C. E. A \& Buunk, B. P. (1993). Commitment processes in close relationships: An independence analysis. Journal of Social and Personal Relationships, 10, 175-204.

Shaver, P., Hazan, C. \& Bradshaw, D. (1988). Love as attachment: the integration of three behavioral systems. Em R. J. Sternberg \& M. L. Barnes (Orgs.). The psychology of love (pp. 68-99). Birghamton: Yale University Press.

Sternberg, R. (1996). Love stories. Personal Relationships, 3, 5979.

Sternberg, R. (1998). Love is a story. New York: Oxford University Press.

Recebido: 10/10/2005

Revisado: 10/11/2005

Aceito: $15 / 12 / 2005$

\section{Sobre os autores:}

Ailton Amélio da Silva: Doutor em Psicologia, psicólogo clínico, escritor, professor do Instituto de Psicologia da USP (ailton@uol.com.br)

Monica Martinez: Doutora em Ciências da Comunicação, professora de jornalismo da UniFiamFaam - Centro Universitário, escritora.

Andréa Soutto Mayor, Thiago de Almeida, Adriana Guimarães Rodrigues, Luiz Maurício de Oliveira: Pós-graduandos do Instituto de Psicologia da USP. 